\section{Safe limits of drinking: patients' views}

The agreed recommendations for safe limits of alcohol consumption from the Royal Colleges of Psychiatrists, General Practitioners, and Physicians ${ }^{1.3}$ are less than 14 units a week for women and less than 21 units a week for men. If these guidelines are to be used by primary health care workers to promote healthy lifestyles, they must be accepted by patients.

The results of a survey three years ago showed that there was little consensus among a sample of experts on the effects of alcohol about the safe limits of alcohol consumption. ${ }^{4}$ A similar study among general practitioners showed that they gave lower limits of alcohol consumption than the experts. ${ }^{5}$ The present study was designed to ascertain what limits of alcohol consumption were considered safe by patients attending their general practitioners.

\section{Subjects, methods, and results}

Nine practices were selected, five in London and four in Oxfordshire. Each practice was given 100 questionnaires and asked to arrange for them to be completed by all patients attending for consultation on one week day. The patients were asked to complete the questionnaire while waiting to see the doctors and to hand the completed questionnaire to them. Each patient's alcohol consumption was assessed by a quantity/frequency question with one unit being equivalent to one half pint of beer, one glass of wine or sherry, or a single measure of spirits. Drinking was classified as light (0-10 units/week), moderate (11-35), or heavy $(\geqslant 36)$. The questionnaire included the question: "In your opinion what is a reasonable or sensible limit that men and women should place on the amount they drink each day if they are to avoid damaging their health?" Patients were asked to give separate answers for subjects who drank only beer, lager, or cider (pints/day); only wine, sherry, or vermouth (glasses/day); and only spirits (single measures/day). Separate answers were sought for men and women. Statistical analysis was by the unpaired Student's $t$ test.

Altogether 561 questionnaires were completed, 298 in London and 263 in Oxfordshire. There were 187 men and 374 women; around a third were under 35 , a third between 35 and 54, and the remainder over 55 years of age. Nearly half the patients thought that two to four units a day were safe. The table summarises the results. For all drinks men gave higher limits of alcohol consumption than women. Heavy drinkers gave higher limits than light drinkers and, with the exception of beer, patients in London gave higher limits than patients in Oxfordshire.

\section{Comment}

The study population was not a random sample but comprised patients attending general practices. Recognising, however, that most preventive care in general practice is undertaken when the opportunity arises, we considered that it was legitimate to study this group of patients. Higher safe limits of alcohol consumption were given for beer than for wines or spirits by both men and women. This may reflect a lack of knowledge of the equivalent alcohol contents of different drinks rather than a belief that beer is safer than wine or spirits. Except for beer, the safe limits given by most patients were well within those recommended by the colleges.

Our results suggest that the safe limits of alcohol consumption recommended by the colleges are generally accepted by patients. Primary care staff should be encouraged to assess each patient's alcohol consumption and if it is above the recommended safe limit advise its reduction.

We thank the nine general practices for helping with the distribution and collection of the questionnaires and Jackie Hodgkinson for typing the manuscript.
1 Royal College of Psychiatrists. Alcohol-our favourite drug. London: Tavistock, 1986. 2 Royal College of General Practitioners. Alcohol-a balanced view. London: Royal College of General Practitioners, 1986

3 Royal College of Physicians. Alcohol-a great and growing evil. London: Tavistock, 1987

4 Anderson $\mathrm{P}$, Cremona $\mathrm{A}$, Wallace $\mathrm{P}$. What are safe levels of alcohol consumption? Br Med $\mathcal{J}$ 1984;289:1657-8.

5 Wallace $\mathrm{P}$, Cremona A, Anderson P. Safe limits of drinking: general practitioners' views. Br Med $\mathcal{J}$ $1985 ; 290: 1875-6$.

(Accepted 29 February 1988)

Department of Community Medicine, Manor House, Headley Way, Headington, Oxford OX3 9DZ

PETER ANDERSON, MSC, MRCGP, senior registrar

Department of General Practice, St Mary's Hospital Medical School, Lisson Grove Health Centre, London

PAUL WALLACE, MSC, MRCGP, senior lecturer

Correspondence to: Dr Anderson.

\section{Regression of rectal adenomas after colectomy and ileorectal anastomosis for familial adenomatous polyposis}

Total colectomy and ileorectal anastomosis for familial adenomatous polyposis has been the procedure of choice for many years in Britain. It is recommended that patients are examined after operation by sigmoidoscopy every three months and that rectal adenomas are fulgurated when necessary. This policy of regular follow up has led to the suggestion, based on subjective clinical impressions of individual cases, that adenomas in the retained rectum may regress after surgery. ${ }^{1-3}$

The aim of this study was to document prospectively, as accurately as possible, any change in the numbers of rectal adenomas after colectomy.

\section{Patients, methods, and results}

Eighteen consecutive patients who had familial adenomatous polyposis and underwent total colectomy and ileorectal anastomosis by one surgeon between 1980 and 1984 were studied. The colon was fully mobilised and the bowel clamped at a distance of $15 \mathrm{~cm}$ from the anal verge as measured by sigmoidoscopy during the operation. The rectum was washed out, and adenomas in the rectum below the clamp were counted. A sigmoidoscope was inserted to the level of the clamp and then withdrawn by intervals of $1 \mathrm{~cm}$, recording the number of adenomas in each interval until the dentate line was reached. The quadrant (posterior, right, anterior, or left) occupied by the adenoma and the approximate size $(<5 \mathrm{~cm},<1 \mathrm{~cm}$, or $<1.5 \mathrm{~cm})$ were noted and recorded.

A second count was performed in the outpatient department during sigmoidoscopy. After a phosphate enema the site of ileorectal anastomosis was identified and the count performed exactly as during the operation. This examination occurred at a median of 10 months (range eight to 32 months) after surgery and in 14 of the 18 cases was carried out by the same person who performed the count during the operation. Wilcoxon's paired rank test was used in statistical analysis of the data.

The figure shows the numbers of adenomas seen during and after surgery. In

Mean (SEM) safe alcohol consumption given for women and men (units/day) by category of respondent

\begin{tabular}{|c|c|c|c|c|c|c|}
\hline \multirow[b]{2}{*}{ Category of respondent } & \multicolumn{3}{|c|}{ Safe No of units for women } & \multicolumn{3}{|c|}{ Safe No of units for men } \\
\hline & Beer & Wine & Spirits & Beer & Wine & Spirits \\
\hline \multicolumn{7}{|l|}{ Sex of respondent: } \\
\hline Men & $3.91(0 \cdot 19)^{\star \star \star}$ & $2 \cdot 47(0 \cdot 10)^{\star \star \star}$ & $2 \cdot 13(0 \cdot 12)^{\star \star \star}$ & $4.89(0.22)^{\star \star}$ & $2 \cdot 83(0 \cdot 12)^{\star \star \star}$ & $2 \cdot 48(0 \cdot 13)^{\star \star \star}$ \\
\hline Women & $3.01(0.01)$ & $1.83(0.06)$ & $1.49(0.05)$ & $4 \cdot 17(0 \cdot 15)$ & $2 \cdot 30(0 \cdot 08)$ & $1.92(0.08)$ \\
\hline \multicolumn{7}{|c|}{ Consumption category of respondent: } \\
\hline Light & $3.07(0.09)^{\star \star \star \star}$ & $1.88(0.05)^{\star \star \star}$ & $1.52(0.05)^{\star \star \star}$ & $3.98(0.12)^{\star \star \star}$ & $2 \cdot 26(0 \cdot 06)^{\star \star \star}$ & $1.89(0.06)^{\star \star \star}$ \\
\hline Moderate & $3.85(0.24)$ & $2 \cdot 50(0 \cdot 14)$ & $2 \cdot 43(0 \cdot 16)$ & $5 \cdot 37(0.25)$ & $3 \cdot 11(0 \cdot 16)$ & $2.98(0 \cdot 16)$ \\
\hline \multirow{2}{*}{\multicolumn{7}{|c|}{ Location of respondent: }} \\
\hline & & & & & & \\
\hline Oxford & $3 \cdot 00(0 \cdot 12)^{\star \star}$ & $1.82(0.07)^{\star \star \star}$ & $1 \cdot 50(0.07)^{\star \star \star}$ & $4 \cdot 00(0 \cdot 16)$ & $2 \cdot 18(0 \cdot 10)$ & $2.28(0.09)^{\star \star \star}$ \\
\hline London & $3 \cdot 47(0 \cdot 13)$ & $2 \cdot 14(0.07)$ & $1.85(0.07)$ & $4 \cdot 55(0 \cdot 15)$ & $2.60(0.08)$ & $1.88(0.08)$ \\
\hline
\end{tabular}

For men compared with women, light drinkers with heavy drinkers, and patients in Oxford with those in London, ${ }^{\star \star} p<0 \cdot 01$ and ${ }^{\star \star \star} p<0 \cdot 001$ respectively. 
patients who had more than 100 polyps areas of apparent confluence were encountered, which made accurate counting above this figure impossible. There was an increase in two patients and no change in another two. In the remaining 14 there was a decrease from a median of 50 (range 2-100) to 22 (range $0-50$ ). Overall the change between the counts during the operation and those after was significant $(p=0.002)$. There was no relation between the size of the decrease and the duration of the interval between counts.

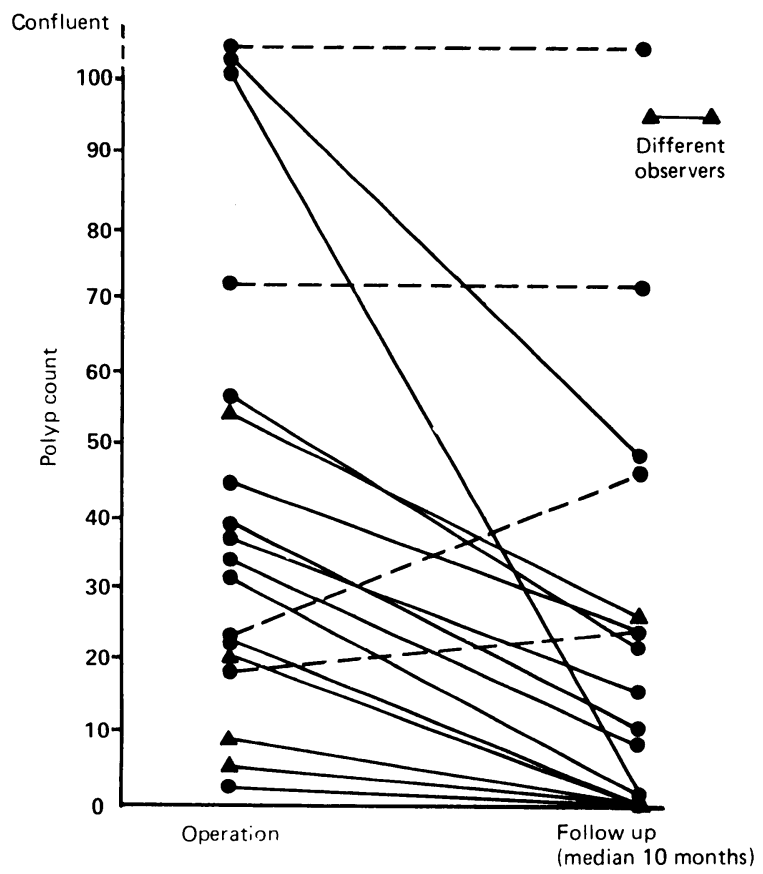

Polyp counts during operation and at follow up

\section{Comment}

Bussey et al have studied the reliability of polyp counting with particular reference to the variation between two observers. ${ }^{+}$They reported counts by different observers to vary by not more than $27 \%$. In the present study a standardised technique and, in most cases, the same observer were used to minimise even this variation. Allowing for a $30 \%$ error in the number of polyps recorded for any pair of observations, the counts obtained in our patients still show a significant decrease.

Many factors have been suggested to account for the regression of polyps. They include a decrease in the $\mathrm{pH}$ of the faecal stream, a reduced rectal blood supply, and the removal of a colonic "stimulating factor." The relation between regression and the development of carcinoma is interesting. It cannot be said that an absence of rectal polyps provides complete protection against carcinogenesis. Several cases of carcinoma in patients who do not have polyps have been recorded. ${ }^{5}$ The question of whether repeated trauma from fulguration or biopsy may be a precipitating factor has been raised. Cancer of the rectum has not been seen in patients who undergo spontaneous regression. ${ }^{3}$ Some patients who undergo regression subsequently develop further adenomas, mainly at the site of anastomosis. Regression of polyps does not reduce the necessity for a policy of intensive surveillance.

1 Hubbard TB. Familial polyposis of the colon: the fate of the retained rectum after colectomy in children. Am Surg 1957;23:577-85

2 Cole JW, Holden WD. Post colectomy regression of adenomatous polyps of the rectum. American Medical Association Archives of Surgen 1959;79:385-92.

3 Williams RD, Fish JC. Multiple polyposis polyp regression and carcinoma of the colon. Am f Surg $1966 ; 112: 8+6-8$.

4 Bussey HJR, De Cosse JJ, Deschner EE, et al. A randomised trial of ascorbic acid in polyposis coli. Cancer 1982:50:1434-9.

5 Hullsiek HE. Multiple polyposis of the colon. Surg Gynecol Obstet 1928;47:346-7.

Accepted 7 March 1988

St Mark's Hospital, London

R J NICHOLLS, MCHIR, FRCS, consultant surgeon

R G SPRINGALL, CHM, FRCS, resident surgical officer

PGALLAGHER, MS, FRCS, resident surgical officer

Correspondence to: Mr R G Springall, Department of Paediatric Surgery, Institute of Child Health, London WCIN 1EH.

\section{Skin fragility and blistering due to use of sunbeds}

We describe six patients in whom prolonged use of sunbeds resulted in skin fragility.

\section{Case histories}

Six patients presented with increased fragility of the skin and formation of blisters in response to minimal trauma. All were unable to obtain more than a minimal tan in natural sunlight because of their tendency to burn and had used ultraviolet $A$ sunbeds for prolonged periods (table).

Use of sunbeds by patients with increased skin fragility

\begin{tabular}{lccccc}
\hline $\begin{array}{l}\text { Case } \\
\text { No }\end{array}$ & $\begin{array}{c}\text { Age } \\
\text { (years) }\end{array}$ & Sex & $\begin{array}{c}\text { Duration of use } \\
\text { (years) }\end{array}$ & $\begin{array}{c}\text { No of sessions/week } \\
\text { (duration of each session } \\
\text { in minutes) }\end{array}$ & $\begin{array}{c}\text { Estimated cumulative } \\
\text { exposure to ultraviolet A } \\
\left(\mathbf{k J} / \mathrm{cm}^{2}\right)^{\star}\end{array}$ \\
\hline 1 & 24 & F & 3 & $4(30)$ & 28 \\
2 & 21 & F & 4 & $5(60)$ & 77 \\
3 & 28 & F & 6 & $2(60)$ & 30 \\
4 & 17 & F & 1 & $2(60)$ & 19 \\
5 & 18 & F & 2 & $4(30)$ & 33 \\
6 & 37 & M & 2 & $7(30)$ & \\
\hline
\end{tabular}

*At presentation all patients were using lamps with an output of $0.1 \mathrm{~kJ} / \mathrm{cm}^{2} / \mathrm{h}$, but some had previously used lamps with lower outputs.

All of the patients were mildly tanned at presentation. The skin on the dorsum of the hands appeared thickened and inelastic. Clear and blood filled blisters had arisen on non-inflamed skin on the dorsum of the hands and feet and on the shins in each patient. Hyperpigmented scars and milia formed when these blisters healed. General examination was normal in all cases. Three patients were taking an oral contraceptive, one sometimes took tablets of frusemide because of ankle swelling, and two were not taking any drugs.

Porphyrin analysis (porphyrias service, Western Infirmary, Glasgow) of blood, urine, and faeces yielded normal results in each case. Histological examination of skin biopsy specimens from four patients showed subepidermal blisters associated with minimal infiltration of the dermis by inflammatory cells. Basement membrane positive for periodic acid Schiff was prominent around dermal blood vessels. Electron microscopy showed separation in the superficial collagen beneath the basal lamina. Specimens from two patients were examined by direct immunofluorescence and showed dense deposition of IgG and C3 along the zone of the epidermal basement membrane and around the blood vessels. Several months after their last exposure on a sunbed four patients were phototested with an irradiation monochromator at $300 \mathrm{~nm}$ (ultraviolet B) and $350 \mathrm{~nm}$ (ultraviolet A). Erythematous responses 24 hours later were within the normal range. Three to six months after the patients abandoned the use of sunbeds some lessening of skin fragility had occurred.

\section{Comment}

Though the clinical features were similar to those of porphyria cutanea tarda, this disease was excluded by the normal results in porphyrin analysis. The relevance of the various drugs taken by some of the patients is not known, but the normal results of phototests in four patients do not support a drug induced phototoxic response. The mechanism of cutaneous damage by ultraviolet $\mathrm{A}$ irradiation is not known, but the level in the skin at which blister formation occurred and the results of direct immunofluorescence are similar to those in epidermolysis bullosa aquisita, ${ }^{12}$ which is thought to be immunologically mediated. Skin fragility after use of a sunbed has been reported previously, but the level of blister formation was not described. ${ }^{3}$

At the time of presentation all of the patients owned solaria (sunbed plus suncanopy) that incorporated fluorescent ultraviolet-A lamps. Our patients' estimated cumulative whole body exposure to ultraviolet A from using sunbed $\left(9-77 \mathrm{~kJ} / \mathrm{cm}^{2}\right)$ is greatly in excess of the exposure of an indoor worker in the United Kingdom (estimated to be $1 \mathrm{~kJ} / \mathrm{cm}^{2} /$ year). ${ }^{4}$ One week of sunbathing at a latitude of $40^{\circ} \mathrm{N}$ would result in a maximum dose of ultraviolet $A$ of around $0.3 \mathrm{~kJ} / \mathrm{cm}^{2}$. Despite the massive exposures each patient achieved only a minimal tan. This contrasts with people who tan easily in natural sunlight, who can achieve a moderate tan in 10-20 half hour sessions on a sunbed (a cumulative exposure to ultraviolet $A$ of $0.5-1.0 \mathrm{~kJ}$ $\mathrm{cm}^{2}$.

Although skin may become more fragile in only a few people who use ultraviolet A sunbeds, people who tan poorly in sunlight or require large doses of ultraviolet $A$ to achieve a tan should be discouraged from using thes sunbeds.

We thank our colleagues for referring these patients and Dr G Bird for performing the direct immunofluorescence. 